\title{
QUEEN'S
UNIVERSITY
BELFAST
}

\section{A new 7-degree-of-freedom 2-PRRRRR parallel remote center-of- motion robot for eye surgery}

Jian, Y., Jin, Y., Price, M., \& Moore, J. (2020). A new 7-degree-of-freedom 2-PRRRRR parallel remote center-ofmotion robot for eye surgery. In 2020 8th IEEE RAS/EMBS International Conference for Biomedical Robotics and Biomechatronics (BioRob) (pp. 891-896). ( 2020 8th IEEE RAS/EMBS International Conference for Biomedical Robotics and Biomechatronics (BioRob)). Institute of Electrical and Electronics Engineers Inc.. https://doi.org/10.1109/BioRob49111.2020.9224344

Published in:

2020 8th IEEE RAS/EMBS International Conference for Biomedical Robotics and Biomechatronics (BioRob)

Document Version:

Peer reviewed version

Queen's University Belfast - Research Portal:

Link to publication record in Queen's University Belfast Research Portal

Publisher rights

Copyright 2020 IEEE. This work is made available online in accordance with the publisher's policies. Please refer to any applicable terms of use of the publisher.

\section{General rights}

Copyright for the publications made accessible via the Queen's University Belfast Research Portal is retained by the author(s) and / or other copyright owners and it is a condition of accessing these publications that users recognise and abide by the legal requirements associated with these rights.

Take down policy

The Research Portal is Queen's institutional repository that provides access to Queen's research output. Every effort has been made to ensure that content in the Research Portal does not infringe any person's rights, or applicable UK laws. If you discover content in the Research Portal that you believe breaches copyright or violates any law, please contact openaccess@qub.ac.uk. 


\title{
A new 7-degree-of-freedom 2-PRRRRR parallel remote center-of-motion robot for eye surgery*
}

\author{
Yinglun Jian, Yan Jin, Mark Price, Johnny Moore
}

\begin{abstract}
Millions of patients suffering from eye disease cannot receive proper treatment due to the lack of qualified surgeons. Medical robots have the potential to solve this problem and consequently are attracting significant attention in the research community. This paper introduces a new 7-degree-of-freedom (DOF) 2-PRRRRR parallel robot with remote-center-of-motion for eye surgery. Mobility requirement, robot mechanism synthesis, kinematics, singularity, and dimensional optimization for the prescribed workspace, are analyzed and presented. A number of configurations were explored focusing on cataract surgery resulting in one being identified that covers the area completely and has excellent dexterity, but further work will be needed to enhance accuracy.
\end{abstract}

\section{INTRODUCTION}

Over 60 million people around the world suffer from visual impairment many of whom could benefit from eye surgery [1]. Approximately one third of such visual impairments are caused by cataracts, which are the largest contributor to blindness in middle and low income countries [2], and second largest in the UK [3] and the US [4]. However, there is a worldwide deficiency in trained eye surgeons, which is particularly prevalent in developing countries. Eye surgery requires highly delicate and precise fine motor skills, which are not common, and cannot always be achieved by training and practice. However, a robot can provide the high precision necessary and has the potential to be an assistance tool for a doctor to achieve effective and efficient high quality surgery in partnership.

Minimally invasive surgery (MIS) uses long and thin surgical tools to complete all the surgical procedures. The tools are inserted into the patient's body through small incisions consequently resulting in only small scars, little blood loss and rapid recovery. These advantages make MIS a popular procedure. However, it does require significant skills as surgeons need to concentrate on keeping surgical tools at these small incisions without enlarging them. For eye surgery such as a cataract surgery, a surgeon typically holds two tools, one in each hand, which are inserted through two incision points, one on each side of the eye to collaboratively tear up the malfunctioned lens and replace it with an artificial one. For each tool, this action requires four degree-of-freedom (DOF)

*Research supported by Cathedral Eye Clinic and Queen's University Belfast.

Yinglun Jian is with the School of Mechanical and Aerospace Engineering, Queen's University Belfast, UK (phone: +44 07864130285; e-mail: yjian01@qub.ac.uk).

Yan Jin is with the School of Mechanical and Aerospace Engineering, Queen’s University Belfast, UK (e-mail: y.jin@qub.ac.uk).

Mark Price is with the School of Mechanical and Aerospace Engineering, Queen's University Belfast, UK (e-mail: m.price@qub.ac.uk).

Johnny Moore is with Cathedral Eye Clinic (e-mail: Johnny@cathedraleye.com). motion including three rotations (3R) about the incision point and one translation (1T) through the incision point. If a robot is to be used to replace the surgeon's hand, it must provide the same 3R1T DOFs after locating the incision point. The incision point is commonly defined as the remote-center-of-motion (RCM) of the robot. In case of the robot, the RCM point has to be a virtual point, with no physical joint over the center in order to avoid the collision with the eye.

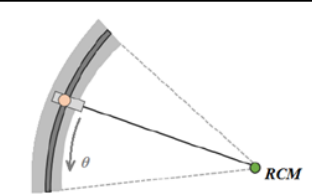

(a)

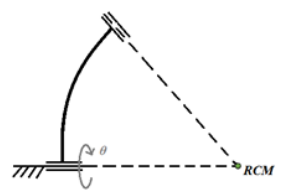

(c)

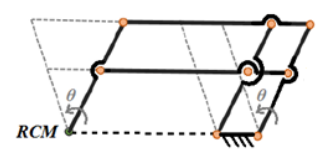

(b)

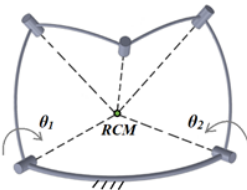

(d)
Figure 1. Four types of RCM mechanisms. (a) Circular rail RCM mechanism. (b) Double-parallelogram RCM mechanism. (c) Serial spherical RCM mechanism. (d) Parallel spherical RCM mechanism.

One way to limit the robotic tool motion in 3R1T DOFs is to apply an RCM mechanism to mechanically constrain the surgical tool. Four types of RCM mechanisms are widely used in MIS robots, i.e. circular rail, double-parallelogram, serial spherical, and parallel spherical. The four types of RCM mechanisms are shown in Fig. 1. One of the first MIS robots for eye surgery with an RCM mechanism was the Stereotaxical Micro-telemanipulator for Ocular Surgery (SMOS) [5], which was proposed by Guerrouad et al. in 1989 SMOS uses the circular rail RCM mechanism, which has also been applied in some MIS robots in the last decade [6]. The Double-parallelogram RCM mechanism is the most widely used in MIS robots. It has been applied to the da Vinci Surgical Robotic System [7] and some recent robots for retinal surgery [8][9]. The double-parallelogram mechanism has many advantages including a simple structure, a large workspace, decoupled motion, and the dynamics are easy to solve. Its disadvantage is relatively low stiffness due to the large number of revolute joints [10]. Some MIS robots apply serial spherical RCM mechanisms [11]. But these tend to have a low precision because of the accumulation of errors propagated through the kinematic chain. Parallel spherical RCM mechanisms recently attracted interests because of their theoretical advantages over serial ones, in particular their high precision, light moving structures and high stiffness [12] Most of them are designed specifically for laparoscopic 
surgery and cannot be directly applied to eye surgery due to different requirements in scale and precision. The small size of human eye limits the workspace and the precision must be very high (10 micro meter [13]) to avoid damage to the eye. Therefore, although the parallel spherical RCM mechanism has potential to provide the required precision, to date, only a few eye surgery robots applying parallel spherical RCM mechanisms have been introduced. DIAMOND is one of the them, which was proposed by Molaei et al. in 2015 [14]. Further research on applying parallel spherical RCM mechanisms specifically for the eye surgery is needed.

In the case of eye surgery the robot part of the challenge is that in addition to the 4-DOF motion for the surgical operation, three more translational DOFs are required to move the robot RCM point coincident with the eye incision point. Therefore, seven DOFs are required for the entire robot system. To date most literature has focused on the 4-DOF surgical motion part while the three translational DOFs have been neglected.

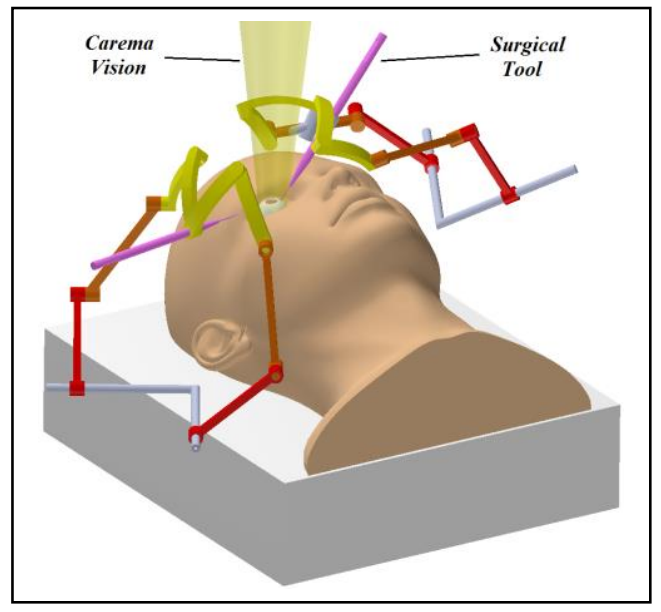

Figure 2. The new 7-DOF parallel RCM mechanism.

In this paper, as shown in Fig. 2, a new 7-DOF 2-PRRRRR ( $\mathrm{R}$ represents rotational joints, $\mathrm{P}$ represents prismatic joints) parallel RCM robot for eye surgery is presented to address the knowledge gaps mentioned above. The following sections will first analyze the requirements of robot-assisted eye surgery, then describe the generation of the new mechanism, analyze the singularity and workspace, and finally conduct the workspace-oriented dimension optimization.

\section{REQUIREMENT OF ROBOT-ASSISTED EYE SURGERY}

\section{A. Cataract Surgery Workflow}

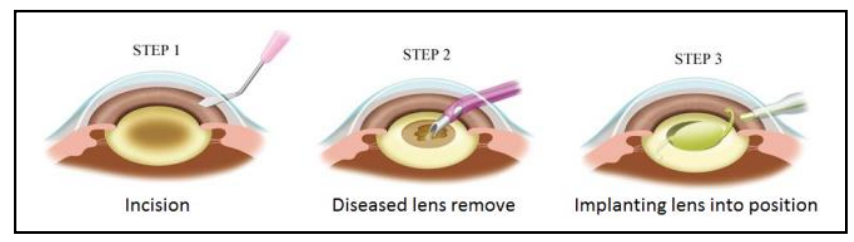

Figure 3. The procedure of cataract surgery [15].

As shown in Fig. 3 [18], cataract surgery is a procedure to remove the lens in the eye and replace it with an artificial lens through small incisions. For robot-assisted cataract surgery, there are five phases in the workflow. Phase I is "approaching", in which the robot approaches the patient's eye and locates its RCM point at the incision point. Phase II is "insertion", which means inserting the surgical tool into the patient's eye through the located incision. Phase III is "manipulation", where the robot manipulates the surgical tool to perform the 3R1T motions that break and remove the diseased lens, implant artificial lens. Phase IV is "removal", which means removing the surgical tool from the patient's eye. Phase V is "leaving", in which the robot moves away from the patient.

\section{B. Specification of the Robot}

It is reported that a precision of 500 microns about an RCM point on the surface of the incision are required for robot-assisted cataract surgery [16]. Considering the potential applications on vitreoretinal surgery, the robot proposed in the herein paper aims to achieve a precision of 10 microns [17]. The speed of the surgical tool is measured by existing manual operation. The tool tip speed of Phase III is less than $1 \mathrm{~mm} / \mathrm{s}$. The tool tip speed of Phase II and Phase IV is $1 \sim 5 \mathrm{~mm} / \mathrm{s}$. The tool tip speed of Phase I and Phase $\mathrm{V}$ is $5 \sim 10 \mathrm{~mm} / \mathrm{s}$. In addition, the majority of forces applied during in-vitro retinal manipulation in porcine cadaver eyes were found to be below $7.5 \mathrm{mN}$ [18]. The design specifications of the robot are shown in Table I.

TABLE I. DESIGN GOALS OF THE ROBOT

\begin{tabular}{|c|c|}
\hline Robot Specification & Value \\
\hline Precision & $10 \mu \mathrm{m}$ \\
\hline Tool tip speed - Phase I \& V & $5 \sim 10 \mathrm{~mm} / \mathrm{s}$ \\
\hline Tool tip speed - Phase II \& IV & $1 \sim 5 \mathrm{~mm} / \mathrm{s}$ \\
\hline Tool tip speed - Phase III & $<1 \mathrm{~mm} / \mathrm{s}$ \\
\hline Force & $7.5 \mathrm{mN}$ \\
\hline
\end{tabular}

\section{Workspace Requirement}

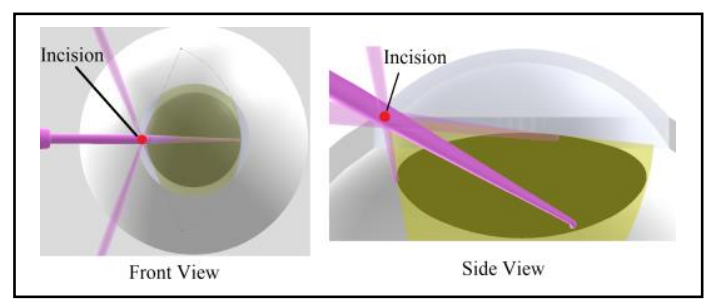

Figure 4. The required workspace.

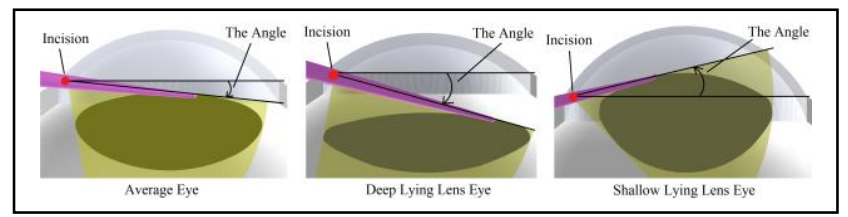

Figure 5. Incisions and the incision angles of all three lens-eye models.

During surgery, the robot must be able to manipulate the surgical tool so that it reaches the whole area of the whole lens through the small incision. The yellow volume in Fig. 4. shows the required workspace based on average human ocular dimensions as presented by Charles and Brown [19]. The incision point is located at the junction of cornea and sclera referred to the usual incision in cataract surgery. Considering the variation in a human eye, apart from the average ocular dimensions, two additional dimensions are used to build 3D lens-eye models. These cover the cases of deep lying lens and 
shallow lying lens [19]. The deep lying lens sits deeply from the cornea with a smallest thickness and a largest diameter. Similarly, the shallow lying lens sits close to the cornea with the largest thickness and the smallest diameter. The three key eye dimensions there include the average condition and two extreme conditions. As shown in Fig. 5, the incision angle in each lens-eye model is recorded.

\section{GENERATION OF THE MECHANISM}

Inspired by a 6-DOF parallel manipulator with decoupled translation and rotation proposed by Jin et al. [20], the conceptual design of a new parallel 7-DOF mechanism is developed. As shown in Fig. 6(a), the 6-DOF parallel manipulator consists of 3 RPPPRR legs. The new 7-DOF parallel RCM mechanism is created in three steps, which is shown in Fig. 6, where the actuated joints are highlighted in red. Firstly, for compactness and ease of access to the patient, one leg of the 6-DOF parallel manipulator is eliminated to create a more compact two leg parallel manipulator, as shown in Fig. 6(b). Then, in Fig. 6(c), considering the designs of Sarrus Mechanism [21], the passive prismatic joints are replaced by passive rotational joints. Finally, in order to achieve the motion requirement analyzed in the last section, the two joints $\mathrm{R}_{\mathrm{E} 1}$ and $\mathrm{R}_{\mathrm{E} 2}$ are coincident with the surgical tool axis, and the actuated joints is $\mathrm{P}_{\mathrm{A} 1}, \mathrm{P}_{\mathrm{A} 2}, \mathrm{R}_{\mathrm{A} 1}, \mathrm{R}_{\mathrm{C} 1}, \mathrm{R}_{\mathrm{C} 2}, \mathrm{R}_{\mathrm{E} 1}$ and $\mathrm{P}_{\mathrm{E} 2}$, which is shown in Fig. 6(d).

Figure 7(a) shows the schematics of one leg of the new 7-DOF parallel RCM mechanism. It is a PRRRRR leg with the axes of the first three $\mathrm{R}$ joints $\mathrm{A}, \mathrm{B}$ and $\mathrm{C}$ parallel to each other, as well as the axes of the last three $\mathrm{R}$ joints $\mathrm{C}, \mathrm{D}$ and $\mathrm{E}$ intersecting at one point, the RCM point, $\mathrm{O}_{\mathrm{RCM}}$.

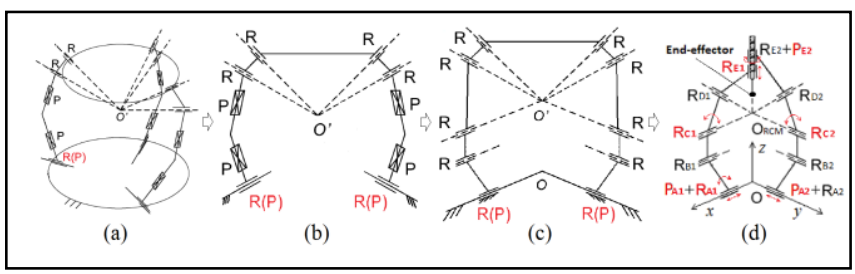

Figure 6. Design process of the new 7-DOF parallel RCM mechanism.

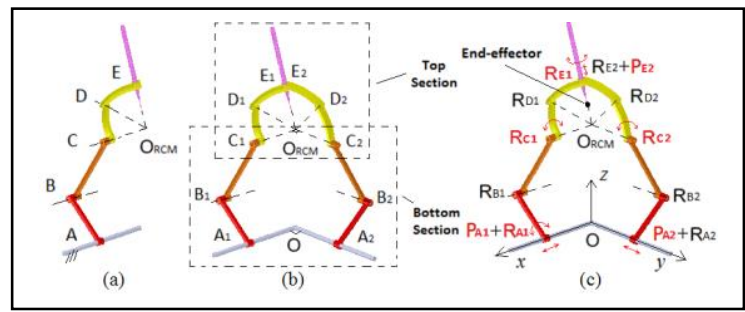

Figure 7. Schematics of the new 7-DOF parallel RCM mechanism. (a) One leg. (b) Two sections. (c) Passive and actuated joints.

As shown in Fig. 7(b), $\mathrm{OA}_{1}$ and $\mathrm{OA}_{2}$ are designed perpendicular to each other to decouple the two translational DOFs on the base. $\mathrm{OA}_{1}$ and $\mathrm{O}_{\mathrm{RCM}} \mathrm{C}_{1}$ are parallel; meanwhile $\mathrm{OA}_{2}$ and $\mathrm{O}_{\mathrm{RCM}} \mathrm{C}_{2}$ are also parallel. Therefore, $\mathrm{O}_{\mathrm{RCM}} \mathrm{C}_{1}$ and $\mathrm{O}_{\mathrm{RCM}} \mathrm{C}_{2}$ are perpendicular to each other. The distances and orientations of $\mathrm{O}_{\mathrm{RCM}} \mathrm{C}_{1}$ and $\mathrm{O}_{\mathrm{RCM}} \mathrm{C}_{2}$ are both determined. As a result, the relative position between $\mathrm{C}_{1}$ and $\mathrm{C}_{2}$ is constant in the new RCM mechanism. Imagining that there is a virtual linkage between $C_{1}$ and $C_{2}$, the top section can be regarded as a five-bar parallel spherical RCM mechanism. The bottom section provides the positioning function to locate the RCM.

The schematics of the new parallel 7-DOF mechanism with passive and actuated joints is shown in Fig. 7(c), where the actuated joints are highlighted in red. The three actuated joints on the base, $\mathrm{P}_{\mathrm{A} 1}, \mathrm{P}_{\mathrm{A} 2}$ and $\mathrm{R}_{\mathrm{A} 1}$, provide 3 translational DOFs along $\mathrm{x}, \mathrm{y}$, and $\mathrm{z}$ axes to locate the RCM to the incision point. The other four actuated joints, $\mathrm{R}_{\mathrm{C} 1}, \mathrm{R}_{\mathrm{C} 2}, \mathrm{R}_{\mathrm{E} 1}$ and $\mathrm{P}_{\mathrm{E} 2}$ manipulate the end-effector to perform a 3R1T DOF motion. $R_{\mathrm{C} 1}$ and $R_{\mathrm{C} 2}$ provide $2 \mathrm{R}$ DOFs to change the orientation of the surgical tool. $\mathrm{R}_{\mathrm{E} 1}$ and $\mathrm{P}_{\mathrm{E} 2}$ provide $1 \mathrm{R} 1 \mathrm{~T}$ DOFs along tool axis. During surgery, the three actuated joints in the bottom section, $\mathrm{P}_{\mathrm{A} 1}, \mathrm{P}_{\mathrm{A} 2}$ and $\mathrm{R}_{\mathrm{A} 1}$ are actuated first with the other four actuated joints locked. When $\mathrm{P}_{\mathrm{A} 1}$ actuates the RCM point, $\mathrm{O}_{\mathrm{RCM}}$, translates along the $\mathrm{x}$ axis. Meanwhile, when $\mathrm{P}_{\mathrm{A} 2}$ actuates the $\mathrm{RCM}$ point, $\mathrm{O}_{\mathrm{RCM}}$, translates along the $\mathrm{y}$ axis. The translation of $\mathrm{O}_{\mathrm{RCM}}$ along the $\mathrm{z}$ axis is controlled by both $\mathrm{P}_{\mathrm{A} 2}$ and $\mathrm{R}_{\mathrm{A} 1}$. When the $y$ coordinate of $\mathrm{O}_{\mathrm{RCM}}$ is determined first, the $\mathrm{z}$ coordinate of $\mathrm{O}_{\mathrm{RCM}}$ is only controlled by $\mathrm{R}_{\mathrm{A} 1}$. As a result, the three translational DOFs are partially decoupled. Once the $\mathrm{O}_{\mathrm{RCM}}$ is positioned, $\mathrm{P}_{\mathrm{A} 1}, \mathrm{P}_{\mathrm{A} 2}$ and $\mathrm{R}_{\mathrm{A} 1}$ are locked. Then the end-effector can perform a 3R1T motion by actuating the other four actuated joints, $\mathrm{R}_{\mathrm{C} 1}, \mathrm{R}_{\mathrm{C} 2}, \mathrm{R}_{\mathrm{E} 1}$ and $\mathrm{P}_{\mathrm{E} 2}$.

All the geometrical constraints are listed below:

- $\quad \mathrm{R}_{\mathrm{i} 1} / / \mathrm{R}_{\mathrm{i} 2} / / \mathrm{R}_{\mathrm{i} 3}$. $(\mathrm{i}=1,2)$

- $\mathrm{OA}_{1} \perp \mathrm{OA}_{2}$.

- The axes of $\mathrm{R}_{\mathrm{C} 1}, \mathrm{R}_{\mathrm{C} 2}, \mathrm{R}_{\mathrm{D} 1}, \mathrm{R}_{\mathrm{D} 2}, \mathrm{R}_{\mathrm{E} 1}$ and $\mathrm{R}_{\mathrm{E} 2}$ intersect at one point, $\mathrm{O}_{\mathrm{RCM}}$.

- $\quad \mathrm{R}_{\mathrm{E} 1}$ and $\mathrm{R}_{\mathrm{E} 2}$ are coincident with the surgical tool axis. Motions are listed below:

- Bottom section: 3T (locate the RCM point).

- Top section: $3 \mathrm{R} 1 \mathrm{~T}$, or $2 \mathrm{R}+1 \mathrm{R} 1 \mathrm{~T}$ (orientate tool axis + roll at and translate along tool axis).

\section{KINEMATICS ANALYSES}

Table II shows the input kinematics parameters of the seven actuators. All the kinematics parameters are illustrated in Fig. 8. All angles are anticlockwise positive. For the $\mathrm{O}$ frame, the $\mathrm{Z}$ axis is along $\mathrm{OA}_{1}$, and the $\mathrm{X}$ axis is along $\mathrm{OA}_{2} . l_{l}$ is the distance of $\mathrm{OA}_{1} ; l_{2}$ is the distance of $\mathrm{OA}_{2} ; \theta_{A l}$ is the angle from the $\mathrm{Y}$ axis to axis $\mathrm{A}_{1} \mathrm{~B}_{1} ; \theta_{B 1}$ is the angle from linkage $\mathrm{A}_{1} \mathrm{~B}_{1}$ to linkage $\mathrm{B}_{1} \mathrm{C}_{1} ; \theta_{C l}$ is the angle from linkage $\mathrm{B}_{1} \mathrm{C}_{1}$ to linkage $\mathrm{C}_{1} \mathrm{D}_{1} ; \theta_{D I}$ is the angle from linkage $\mathrm{C}_{1} \mathrm{D}_{1}$ to linkage $\mathrm{D}_{1} \mathrm{E}_{1} ; \theta_{A 2}$ is the angle from $\mathrm{Y}$ axis to axis $\mathrm{A}_{2} \mathrm{~B}_{2} ; \theta_{B 2}$ is the angle from linkage $\mathrm{A}_{2} \mathrm{~B}_{2}$ to linkage $\mathrm{B}_{2} \mathrm{C}_{2} ; \theta_{C 2}$ is the angle from linkage $\mathrm{B}_{2} \mathrm{C}_{2}$ to linkage $\mathrm{C}_{2} \mathrm{D}_{2} ; \theta_{D 2}$ is the angle from linkage $\mathrm{C}_{2} \mathrm{D}_{2}$ to linkage $\mathrm{D}_{2} \mathrm{E}_{2} . d_{1}$ is both the length of linkage $\mathrm{A}_{1} \mathrm{~B}_{1}$ and linkage $\mathrm{A}_{2} \mathrm{~B}_{2} ; d_{2}$ is both the length of linkage $\mathrm{B}_{1} \mathrm{C}_{1}$ and linkage $\mathrm{B}_{2} \mathrm{C}_{2} . r$ is all the length of $\mathrm{O}_{\mathrm{RCM}} \mathrm{C}_{1}, \mathrm{O}_{\mathrm{RCM}} \mathrm{C}_{2}$, $\mathrm{O}_{\mathrm{RCM}} \mathrm{D}_{1}, \mathrm{O}_{\mathrm{RCM}} \mathrm{D}_{2}$ and $\mathrm{O}_{\mathrm{RCM}} \mathrm{E}_{1} . \alpha_{0}$ is the angle from $\mathrm{O}_{\mathrm{RCM}} \mathrm{C}_{1}$ to $\mathrm{O}_{\mathrm{RCM}} \mathrm{C}_{2} . \alpha_{1}$ is both the angle from $\mathrm{O}_{\mathrm{RCM}} \mathrm{C}_{1}$ to $\mathrm{O}_{\mathrm{RCM}} \mathrm{D}_{1}$, and the angle from $\mathrm{O}_{\mathrm{RCM}} \mathrm{C}_{2}$ to $\mathrm{O}_{\mathrm{RCM}} \mathrm{D}_{2} ; \alpha_{2}$ is both the angle from axes $\mathrm{O}_{\mathrm{RCM}} \mathrm{D}_{1}$ to $\mathrm{O}_{\mathrm{RCM}} \mathrm{E}_{1}$, and the angle from $\mathrm{O}_{\mathrm{RCM}} \mathrm{D}_{2}$ to $\mathrm{O}_{\mathrm{RCM}} \mathrm{E}_{2}$. The tool central point (TCP/End-effector) is the tool tip point. $l_{T}$ is the distance of $\mathrm{E}_{1} \mathrm{TCP}$. 
TABLE II. ACTUOATORS AND CORRESPONDING INPUT PARAMETERS

\begin{tabular}{|c|c|c|c|c|c|c|c|}
\hline Actuators & $\mathrm{P}_{\mathrm{A} 1}$ & $\mathrm{P}_{\mathrm{A} 2}$ & $\mathrm{R}_{\mathrm{A} 1}$ & $\mathrm{R}_{\mathrm{C} 1}$ & $\mathrm{R}_{\mathrm{C} 2}$ & $\mathrm{R}_{\mathrm{E} 1}$ & $\mathrm{P}_{\mathrm{E} 2}$ \\
\hline Parameters & $l_{1}$ & $l_{2}$ & $\theta_{A 1}$ & $\theta_{C 1}$ & $\theta_{C 2}$ & $\theta_{T}$ & $l_{T}$ \\
\hline
\end{tabular}

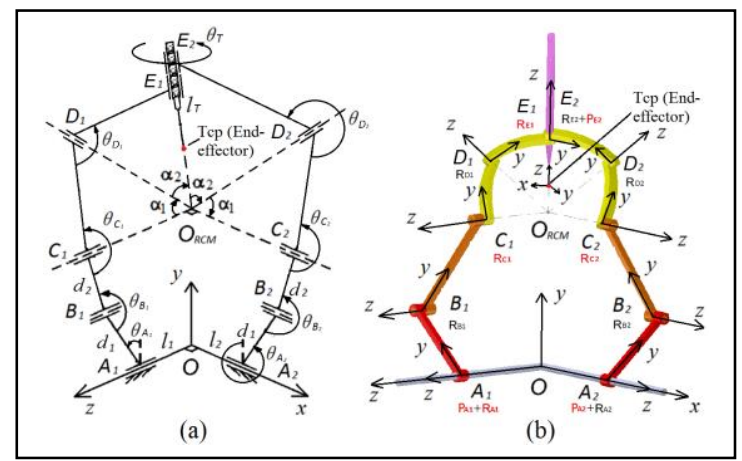

Figure 8. (a) Schematics of the 7-DOF parallel RCM mechanism with

kinematics parameters. (b) 3D model with kinematics parameters.

Following the Denavit-Hatenberg (D-H) frame assignment, frames are assigned to the mechanism joints where the $\mathrm{Z}$ axis of each frame points outward along the corresponding joint, and the $\mathrm{X}$ axis of each frame is along the linkage that links the next joint. D-H parameters are summarized in Table III. The transformation matrix is the typical $4 \times 4$ translation and rotation matrix, as shown in (1).

TABLE III. D-H PARAMETERS

\begin{tabular}{|c|c|c|c|c|c|c|}
\hline $\mathbf{i}-1$ & $\mathbf{i}$ & $\theta_{\mathbf{i}}$ & $\boldsymbol{\alpha}_{\mathbf{i}}$ & $\boldsymbol{x}_{\boldsymbol{i}}-\boldsymbol{x}_{\boldsymbol{i}-1}$ & $\boldsymbol{y}_{\boldsymbol{i}}-\boldsymbol{y}_{\boldsymbol{i}-1}$ & $z_{i-z_{i-1}}$ \\
\hline $\mathrm{O}$ & $\mathrm{A} 1$ & 0 & 0 & 0 & 0 & 1 \\
\hline $\mathrm{A} 1$ & $\mathrm{~B} 1$ & $\theta_{A 1}$ & 0 & $-d_{1} \sin \theta_{A 1}$ & $d_{1} \cos \theta_{A 1}$ & 0 \\
\hline $\mathrm{B} 1$ & $\mathrm{C} 1$ & $\theta_{B 1}$ & 0 & $-d_{2} \sin \theta_{B 1}$ & $d_{2} \cos \theta_{B 1}$ & 0 \\
\hline $\mathrm{C} 1$ & $\mathrm{D} 1$ & $\theta_{C 1}$ & $\alpha_{1}$ & $-r \sin \alpha_{1} \sin \theta_{C 1}$ & $r \sin \alpha_{1} \cos \theta_{C 1}$ & $-r\left(1-\cos \alpha_{1}\right)$ \\
\hline $\mathrm{D} 1$ & $\mathrm{E} 1$ & $\theta_{D 1}$ & $\alpha_{2}$ & $-r \sin \alpha_{2} \sin \theta_{D I}$ & $r \sin \alpha_{2} \cos \theta_{D 1}$ & $-r\left(1-\cos \alpha_{2}\right)$ \\
\hline $\mathrm{E} 1$ & $\mathrm{TCP}$ & $\theta_{T}$ & 0 & 0 & 0 & $l_{T}$ \\
\hline $\mathrm{O}$ ' & $\mathrm{A} 2$ & 0 & 0 & 0 & 0 & 1 \\
\hline $\mathrm{A} 2$ & $\mathrm{~B} 2$ & $\theta_{A 2}$ & 0 & $-d_{1} \sin \theta_{A 2}$ & $d_{1} \cos \theta_{A 2}$ & 0 \\
\hline $\mathrm{B} 2$ & $\mathrm{C} 2$ & $\theta_{B 2}$ & 0 & $-d_{2} \sin \theta_{B 2}$ & $d_{2} \cos \theta_{B 2}$ & 0 \\
\hline $\mathrm{C} 2$ & $\mathrm{D} 2$ & $\theta_{C 2}$ & $\alpha_{1}$ & $-r \sin \alpha_{1} \sin \theta_{C 2}$ & $r \sin \alpha_{1} \cos \theta_{C 2}$ & $-r\left(1-\cos \alpha_{1}\right)$ \\
\hline $\mathrm{D} 2$ & $\mathrm{E} 2$ & $\theta_{D 2}$ & $\alpha_{2}$ & $-r \sin \alpha_{2} \sin \theta_{D 2}$ & $r \sin \alpha_{2} \cos \theta_{D 2}$ & $-r\left(1-\cos \alpha_{2}\right)$ \\
\hline \multicolumn{7}{|c}{} \\
\end{tabular}

where

$$
\begin{gathered}
{ }_{i=1}^{i} R=\left[\begin{array}{ccc}
\cos \theta_{i} & -\sin \theta_{i} \cos \alpha_{i} & \sin \theta_{i} * \sin \alpha_{i} \\
\sin \theta_{i} & \cos \theta_{i} * \cos \alpha_{i} & -\cos \theta_{i}^{*} \sin \alpha_{i} \\
0 & \sin \alpha_{i} & \cos \alpha_{i}
\end{array}\right], \\
{ }_{i-1}^{i} P=P_{i}-P_{i-1}=\left[\begin{array}{c}
x_{i}-x_{i-1} \\
y_{i}-y_{i-1} \\
y_{i}-y_{i-1}
\end{array}\right], \\
{\left[\begin{array}{c}
P_{i} \\
1
\end{array}\right]={ }_{i-1}^{i} T\left[\begin{array}{c}
P_{i-1} \\
1
\end{array}\right]=\left[\begin{array}{c}
x_{i} \\
y_{i} \\
z_{i} \\
1
\end{array}\right]}
\end{gathered}
$$

$P_{i}$ is the vector from $\mathrm{O}$ to the corresponding joint.

The frame of $\mathrm{O}^{\prime}$ is calculated in (5).

$$
\left[\begin{array}{c}
P_{O^{\prime}} \\
1
\end{array}\right]=\left[\begin{array}{cccc}
\cos 90^{\circ} & 0 & \sin 90^{\circ} & 0 \\
0 & 1 & 0 & 0 \\
-\sin 90^{\circ} & 0 & \cos 90^{\circ} & 0 \\
0 & 0 & 0 & 1
\end{array}\right]\left[\begin{array}{c}
P_{O} \\
1
\end{array}\right]
$$

Using this kinematics model, the forward kinematics was calculated and two solutions were found. As shown in Fig. 9, one solution with $\psi$ larger than $180^{\circ}$ is called Up-configuration, the other solution with $\psi$ smaller than $180^{\circ}$ is called Down-configuration. $\psi$ is the angle from linkage $E_{2} D_{2}$ to $E_{1} D_{1}$ anticlockwise.

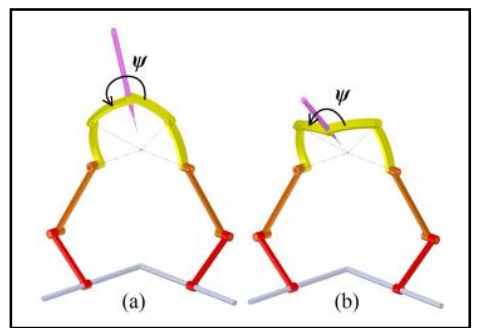

Figure 9. The two solutions in forward kinematics. (a) Up-configuration. (b) Down-configuration.

\section{Singularity AND WorkSPaCE ANALYSES}

The difference of the two configurations are entirely in the top section of the mechanism (shown in Fig. 9). In order to find which configuration is more suitable for robot-assisted eye surgery, the singularity and workspace of the top section are analyzed here.

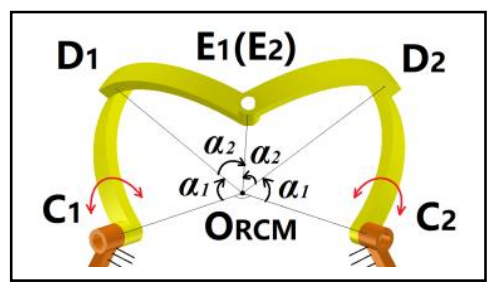

Figure 10. The 2-DOF 5-bar spherical parallel mechanism.

\section{A. Singularity Analysis}

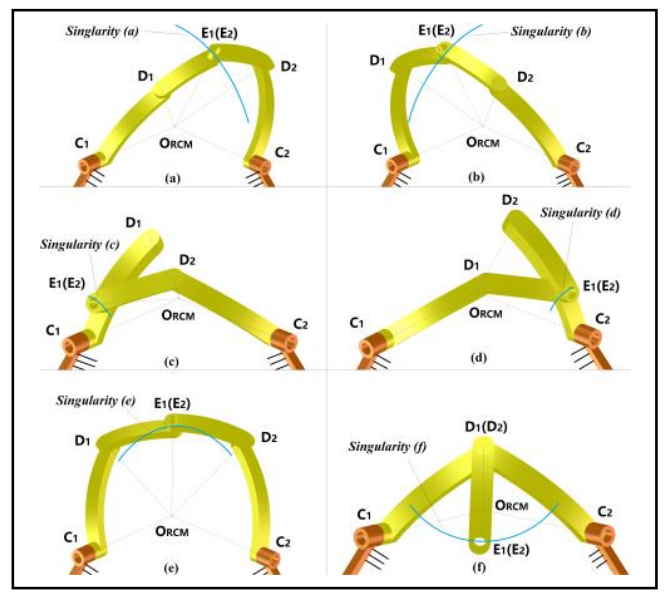

Figure 11. The six types of singularities of the 2-DOF 5-bar spherical parallel mechanism.. 


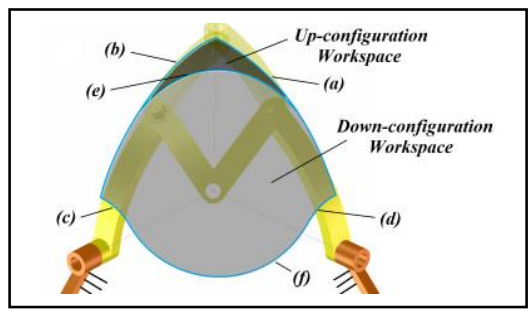

Figure 12. The singularities and workspace of $E_{1}$.

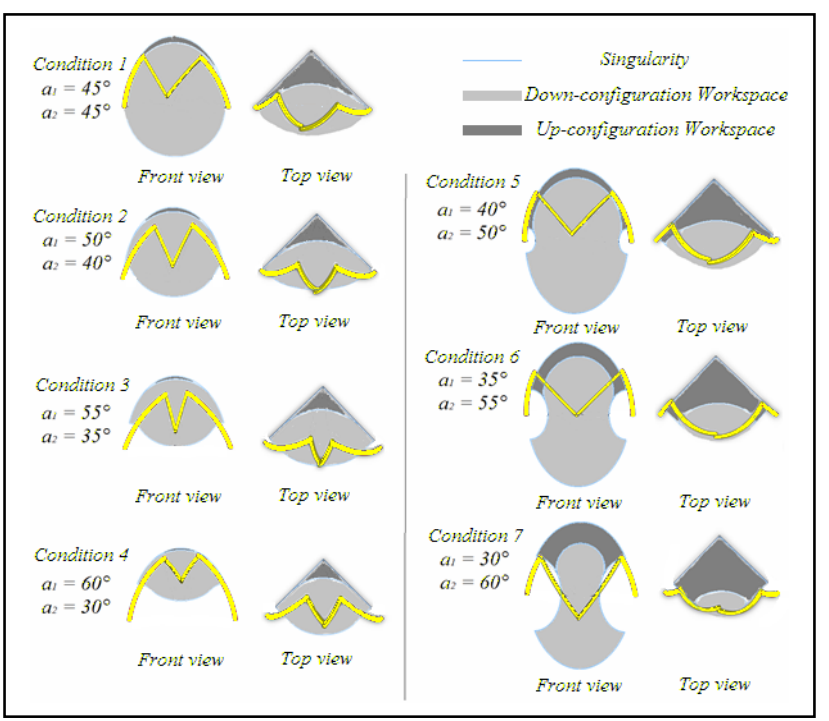

Figure 13. The singularities and workspace of the $\mathrm{E}_{1}$ in different conditions.

In the top section, a singularity appears when two adjacent linkages parallel to each other. For the 3R1T DOF motion in the top section, the 1R1T DOFs are not related to the singularity. When we ignore the 1R1T DOFs and lock the 3T DOFs in bottom section, the top section of the mechanism can be regarded as a 2-DOF 5-bar spherical parallel mechanism.

In this case, shown in Fig. 10, the coordinates of $\mathrm{C}_{1}$ and $\mathrm{C}_{2}$ are fixed, meanwhile $\mathrm{E}_{1}$ performs as the End-effector. The blue curves in Fig. 11, illustrates the six types of singularities classified. Singularity (a) in Fig. 11(a) appears when linkages $\mathrm{C}_{1} \mathrm{D}_{1}$ and $\mathrm{D}_{1} \mathrm{E}_{1}$ are parallel to each other without coinciding. Singularity (b) in Fig. 11(b) appears when linkages $C_{2} D_{2}$ and $\mathrm{D}_{2} \mathrm{E}_{2}$ are parallel to each other without coinciding. Singularity (c) in Fig. 11(c) appears when linkages $\mathrm{C}_{1} \mathrm{D}_{1}$ and $\mathrm{D}_{1} \mathrm{E}_{1}$ coincide. Singularity (d) in Fig. 11(d) appears when linkages $\mathrm{C}_{2} \mathrm{D}_{2}$ and $\mathrm{D}_{2} \mathrm{E}_{2}$ coincide. Singularity (e) in Fig. 11(e) appears when linkages $D_{1} E_{1}$ and $D_{2} E_{2}$ are parallel to each other without coinciding. Singularity (f) in Fig. 11(f) appears when linkages $\mathrm{D}_{1} \mathrm{E}_{1}$ and $\mathrm{D}_{2} \mathrm{E}_{2}$ coincide. As shown in Fig. 12, Singularities $(a)(b)(c)(d)(f)$ form the boundary of the workspace of $E_{1}$, meanwhile Singularity (e) divides the workspace of $\mathrm{E}_{1}$ into two parts, Up-configuration workspace and Down-configuration workspace.

Figure 13 shows the Up-configuration and Down-configuration workspaces in different conditions. Among all conditions, $\alpha_{1}$ and $\alpha_{2}$ vary while the sum of $\alpha_{1}$ and $\alpha_{2}$ is kept as $90^{\circ}$ to fix singularities (a)(b). It is obvious that in all the seven conditions, the Up-configuration workspace is larger than the Down-configuration workspace. As a result, Down-configuration is chosen for the new mechanism.

\section{WORKSPACE-ORIENTED DIMENSION OPTIMIZATION}

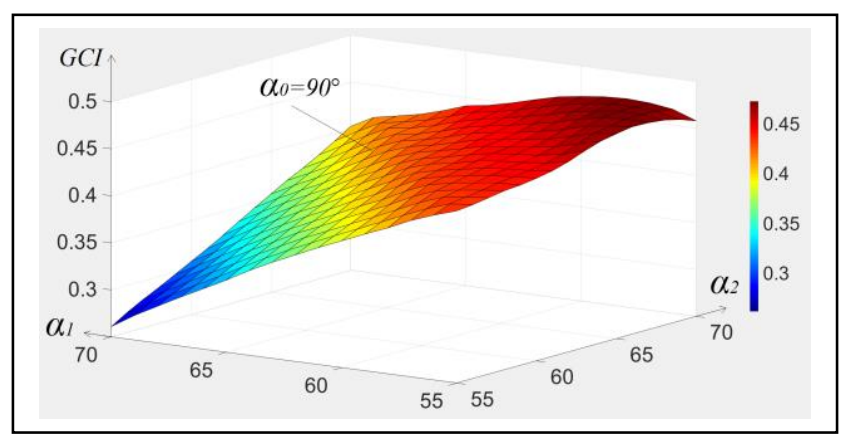

Figure 14. The GCI of all sets of $\alpha_{1}$ and $\alpha_{2}$.

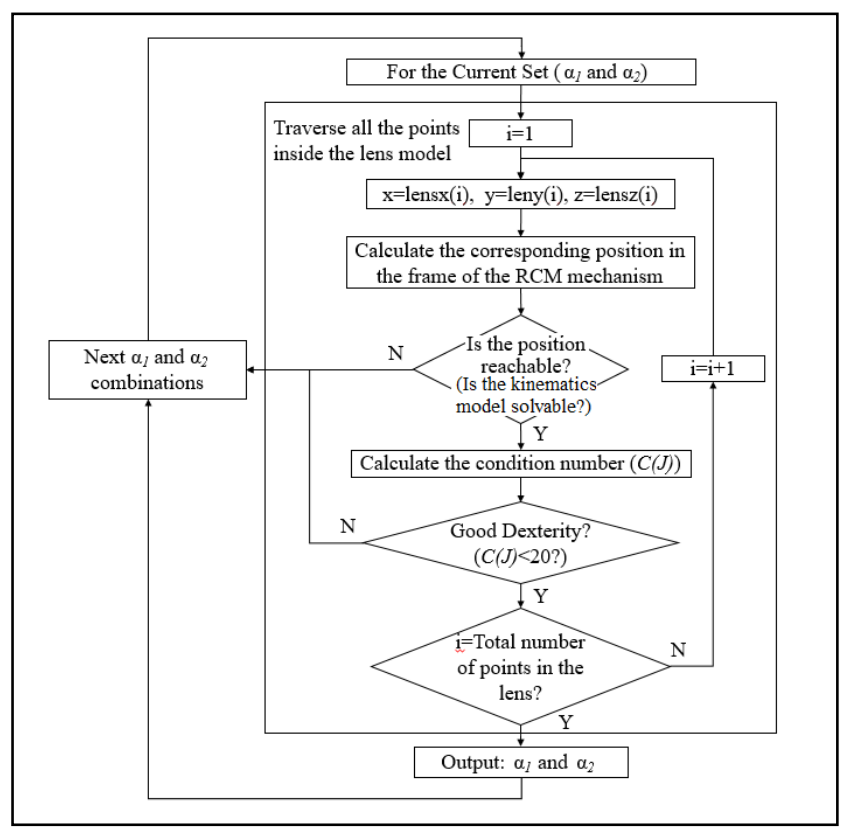

Figure 15. Flow chart of the dimension optimization program.

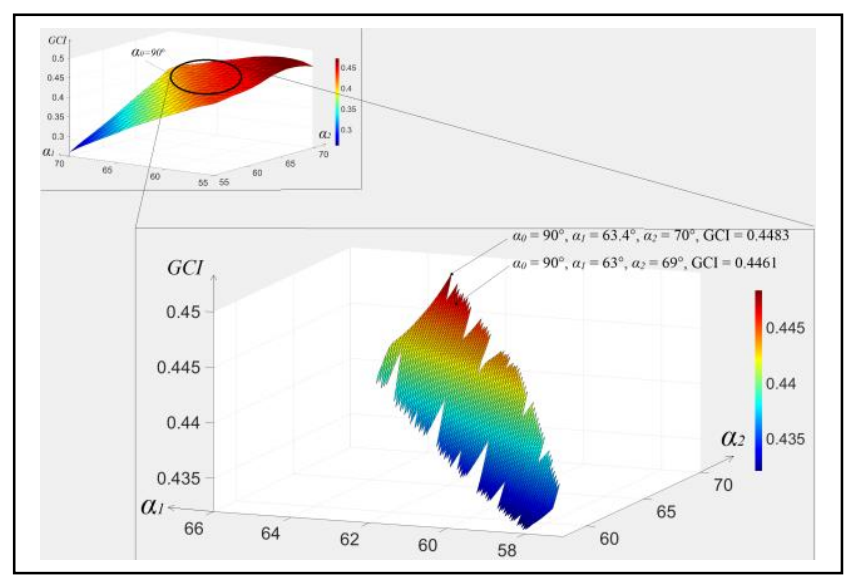

Figure 16. The GCIs of the qualified sets of $\alpha_{1}$ and $\alpha_{2}$.

In this section, the two angle parameters, $\alpha_{1}$ and $\alpha_{2}$, are optimized to achieve two objectives. The first is to meet the workspace requirement of cataract surgery. The second is to make the dexterity of the mechanism in the workspace as good as possible. For the first objective, as the 3D lens-eye models 
are built (Section II), all coordinates of the points inside the lens are covered. By traversing every point and testing if it is reachable by the mechanism, the qualified sets of $\alpha_{1}$ and $\alpha_{2}$ are found. For the second objective, Global Condition Index (GCI) [22] is used to evaluate dexterity. In the workspace-oriented dimension optimization, firstly, as show in Fig. 14, the GCI of the mechanism in each set of $\alpha_{1}$ and $\alpha_{2}$ in average lens-eye model is calculated. Then, by running the program shown in Fig. 15, the qualified sets of $\alpha_{1}$ and $\alpha_{2}$ are picked up. Results are shown in Fig. 16.

In Fig. 15, firstly, for each point inside the lens, the coordinates of the point are obtained from the 3D lens-eye models. Then, these coordinates are used to calculate the corresponding position in the frame of the mechanism. To achieve the two objectives of dimension optimization, every corresponding kinematics model should be solvable to ensure the robot can reach the position, as well as the condition number of each position being smaller than 20 for good dexterity. If either of the requirements is not met in any point traversed, the current set of $\alpha_{1}$ and $\alpha_{2}$ cannot achieve the dimension optimization objectives. This is repeated for every set. When every point is reachable with the condition number smaller than 20, the current set is qualified. The program works for all three 3D lens-eye models (Section II). By running this program three times using all three 3D lens-eye models, the sets of $\alpha_{1}$ and $\alpha_{2}$ qualify all three lens-eye models are found.

Figure 16 shows the GCI of qualified sets of $\alpha_{1}$ and $\alpha_{2}$. The largest GCI occurs at the set $\alpha_{1}=63.4^{\circ}$ and $\alpha_{2}=70^{\circ}$, which is 0.4483 . For easier manufacturing, the qualified sets with integral angle parameters are more attractive. The largest GCI of integral qualified sets occurs at the set $\alpha_{1}=63^{\circ}$ and $\alpha_{2}=69^{\circ}$, which is 0.4461 . As a result, the optimized dimension is $\alpha_{1}=63^{\circ}$ and $\alpha_{2}=69^{\circ}$.

\section{CONCLUSION}

In this paper, a new 7-DOF 2-PRRRRR parallel RCM robot for eye surgery is presented. Its parallel design brings theoretically high stiffness and high precision. There are only eight linkages in the new robot, which contribute to a light structure and small inertia. By analyzing the singularity and workspace of $\mathrm{E}_{1}$, one configuration (the Down-configuration) has been shown to meet the design criteria. The workspace-oriented dimension optimization ensures the new robot for manipulating the surgical tool such that it can reach the whole area required in cataract surgery maintaining very good dexterity.

Further research will focus on building a prototype with control system and calibration, followed by tests to evaluate the accuracy of the new mechanism.

\section{REFERENCES}

[1] GBD 2015 Disease and Injury Incidence and Prevalence, Collaborators, "Global, regional, and national incidence, prevalence, and years lived with disability for 310 diseases and injuries, 1990-2015: a systematic analysis for the Global Burden of Disease Study 2015," Lancet, 388 (10053): 1545-1602.

[2] G. Rao, R. Khanna and A. Payal, "The global burden of cataract," Current Opinion in Ophthalmology, 22(1):4-9, January 2011.
[3] Royal National Institute of Blind People (RNIB), "Sight Loss Data Tool key information and statistics on sight loss in the UK," https://www.rnib.org.uk/professionals/knowledge-and-research-hub/k ey-information-and-statistics, accessed on Nov 12th, 2019.

[4] Royal National Institute of Blind People (RNIB), "Incidence and risk of sight loss and blindness in the UK," August 25th, 2017.

[5] A. Guerrouad and P. Vidal, "S.M.O.S.: Stereotaxical Microtelemanipulator for Ocular Surgery," IEEE Engineering in Medicine \& Biology Society 11th Annual International Conference, 1989.

[6] J.T. Wilson, M.J. Gerber, S.W. Prince, C. Chen, S.D. Schwartz, J. Hubschman, and T. Tsao, "Intraocular robotic interventional surgical system (IRISS): Mechanical design, evaluation, and master-slave manipulation," International Journal of Medical Robotics and Computer Assisted Surgery, 2017, e1842.

[7] Da Vinci Robotic Assisted Surgical Systems, https://www.intuitive.com/, Intuitive Surgical, accessed on Nov 12th, 2019.

[8] T.L. Edwards, K. Xue, H.C.M. Meenink, M.J. Beelen, G.J.L. Naus, M.P. Simunovic, M. Latasiewicz, A.D. Farmery, M.D. de Smet and R.E. MacLaren, "First-in-human study of the safety and viability of intraocular robotic surgery," Nature Biomedical Engineering, 2018, 2(9), 649-656.

[9] A. Gijbels, J. Smits, L. Schoevaerdts, K. Willekens, E.B. Vander Poorten, P. Stalmans and D. Reynaerts, "In-Human Robot-Assisted Retinal Vein Cannulation, A World First," Annals of Biomedical Engineering, 46(10), 1676-1685, 2018.

[10] S. Aksungur and T. Koca, "Remote Center of Motion (RCM) Mechanisms for Surgical Operations", International Journal of Applied Mathematics, Electronics and Computers, 2015, 3(2), p119-126.

[11] B. Hannaford, J. Rosen, D.W. Friedman, H. King, P. Roan, L. Cheng, D. Glozman, J. Ma, S.N. Kosari and L. White, "Raven-II: An Open Platform for Surgical Robotics Research", IEEE Transactions On Biomedical Engıneering, Vol. 60, No. 4, April 2013.

[12] J.K. Hsu, T. Li and S. Payandeh, "On Integration of a Novel Minimally Invasive Surgery Robotic System", IEEE, 2005, p. 437-444.

[13] H.C.M. Meenink, "Vitreo-retinal eye surgery robot: sustainable precision", Eindhoven: Technische Universiteit Eindhoven, 2011.

[14] A. Molaei, E. Abedloo, H.D. Taghirad and Z. Marvi, "Kinematic and Workspace Analysis of DIAMOND: An Innovative Eye Surgery Robot," 2015 23rd Iranian Conference on Electrical Engineering (ICEE).

[15] Cataract-iol, "Cataract Treatment Method," https://www.cataract-iol.jp/treatment/method/, accessed on Nov 12th, 2019.

[16] M. Francom, C. Burns, ..., and P. Ben-Tzvi, "Development of autonomous robotic cataract surgery device", Proceedings of the ASME 2016 International Design Engineering Technical Conferences and Computers and Information in Engineering Conference, August 21-24, 2016, Charlotte, North Carolina.

[17] J. R. Wilkins, C. A. Puliafito, M. R. Hee, 1. S. Duker, E. Reichel, J. G. Coker, 1. S. Schuman, E. A. Swanson and 1. G. Fujimoto, "Characterization of epiretinal membranes using optical coherence tomography," Ophthalmology, vol. 103, no. 12, pp. 2142-2151, Dec. 1996.

[18] P. Gupta, P. Jensen and E. de Juan, "Surgical forces and tactile perception during retinal microsurgery," in Medical Image Computing and Computer-Assisted Intervention (MICCAI'99), vol. 1679 of Lecture Notes in Computer Science, pp. 1218-1225, Springer Berlin / Heidelberg, 1999.

[19] M. W. Charles and N. Brown, "Dimensions of the Human Eye Relevant to Radiation Protection," Physics in Medicine \& Biology, 1975, Vol. 20, No. 2, 202-218.

[20] Y. Jin, I.-M. Chen and G. Yang, "Kinematic Design of a 6-DOF Parallel Manipulator with Decoupled Translation and Rotation," IEEE Transactions on Robotics, vol. 22, no. 3, June 2006.

[21] K.J. Waldron, "Hybrid Overconstrained Linkages," Journal of Mechanisms, 3(2), pp. 73-78, 1968.

[22] C. Gosselin and J. Angeles, "A global performance index for the kinematic optimization of robotic manipulators," ASME Journal of Mechanical Design, 113:220-226, 1991. 